Research Article

\title{
Simulation Study on Friction and Wear Law of Brake Pad in High-Power Disc Brake
}

\author{
S. Zhang $\left(\mathbb{D}\right.$, Q. Hao $\mathbb{D}^{\text {, }, ~ Y . ~ L i u ~}\left(\mathbb{D}\right.$, L. Jin, F. Ma $\mathbb{D}^{D}$, Z. Sha, and D. Yang \\ School of Mechanical Engineering, Dalian Jiaotong University, Dalian 116028, China \\ Correspondence should be addressed to Y. Liu; liuyu_ly12@126.com
}

Received 20 March 2019; Revised 18 June 2019; Accepted 1 July 2019; Published 14 July 2019

Academic Editor: Mohammad Uddin

Copyright (c) 2019 S. Zhang et al. This is an open access article distributed under the Creative Commons Attribution License, which permits unrestricted use, distribution, and reproduction in any medium, provided the original work is properly cited.

\begin{abstract}
For the serious and uneven wear of the brake pad in the high-power disc brake during braking, the dynamic variation of the brake disc and the brake pad interface variable is considered, the wear calculation model is established based on the friction and wear mechanism, and the wear depth and volume of the brake pad can be calculated by equations. A finite element model of the brake disc and the brake pad is established by DEFORM software which can analyze wear of the brake pad directly. The variation trend of wear during braking is studied, and influences of braking load and initial braking speed on the wear are analyzed. The results show that the amount of the wear increases rapidly in the early wear stage of braking, and it becomes slow in the later stage; the wear of the brake pad is serious at the friction inlet and outlet, and the middle area of the brake pad is lightly worn; heavy braking load and high initial braking speed can exacerbate the wear of the brake pad.
\end{abstract}

\section{Introduction}

Disc brakes are widely used in aircrafts, automobiles, cranes, wind turbines, and other mechanical equipments, and it is a significant component to ensure the operation safety of machine. Because of the advantages of stable braking performance and large torque capacity, the disc brake has become one of the most advanced brake devices. Under highpower emergency braking condition, the disc brake is used to stop the high-speed brake disc with heavy load. During the entire braking process, a large amount of friction heat is generated by the friction effect of the brake disc and pad, resulting in heat fade and thermal damage on the brake pad [1]. A small part of friction heat is stored in friction material as internal energy. Deformation and wear of material could occur on the brake pad because of uneven distribution of the large amount of heat. The friction heat causes localized high temperature of contact surface and uneven thermal deformation of the brake pad. These above result in an uneven distribution of the contact stress between the brake disc and pad. Because of the braking performance degradation corresponding to the variation of the wear condition of the brake disc and pad, friction and wear analysis of high-power disc brake has become a research hotspot all over the world.
Friction heat distributes unevenly due to various reasons, such as thermal expansion and geometrical defects. It is well known that thermoelastic distortion affects the contact stress distribution and leads to thermoelastic instability, or where the contact stress is concentrated in one or more small regions on the brake disc surface. These regions then get very high temperatures with low frequency vibration. Disc thickness variation will further promote the localized contact. Nonuniform contact can also be generated by disc lateral runout. Lee et al. investigated the effects of various contact conditions on the heating patterns and judder characteristics of a disc brake. The baseline friction material used in the study was modified based on the theory of thermoelastic instability and dynamometer testing [2]. Then, numerical techniques had been developed to characterize the contact temperature problem of composite materials, and the contact temperature distribution between real composite-steel surfaces could be evaluated in sliding contact [3]. Therefore, some researchers examined finite element models for studying the friction heat of the disc brake to obtain the temperature distribution and the thermal and residual stresses [4-6].

The generation of friction heat is affected by the braking conditions, determined by the braking parameters. The braking parameters have a major impact on the wear. Yevtushenko 
et al. studied the numerical simulation of frictional heating in a disc brake of a typical passenger vehicle based on the equation of motion and the boundary-value problem of heat conduction. An influence of temperature-dependent coefficient of friction on the braking parameters was studied [7]. Sergienko et al. studied a dimensionless heat problem for a friction pair of a multidisc brake under conditions of a linear decrease in the friction power of discs with time. Thermal state of friction pairs of the multidisc brake under load and velocity conditions of the friction of the discs that simulate service braking of a wheel tractor was experimentally and theoretically studied [8]. Accounting for the initial decrease and the subsequent increase in the frictional forces with increasing relative velocity, Kaliyannan et al. considered a negative gradient friction model and obtained approximate analytical expressions for the amplitudes and base frequencies of friction-induced stick-slip and pure-slip phases of oscillations [9]. Liu et al. proposed an iterative integration method to analyze parametric instabilities and compared with an established numerical method. The impacts of friction coefficient, bending effect, contact ratio, and modal damping on the stability boundaries were revealed [10]. Rezaei et al. employed an adaptive wear modeling method to study the wear progress in radial sliding bearings contacting with a rotary shaft.

In the developed wear processor algorithm, remeshing not only was performed on the contact elements but also was executed for their proximity elements. The simulations also demonstrated how the contact pressure evolved during the wear process and how the clearance influenced this evolution [11]. Bortoleto et al. presented a computational study based on the linear Archard's wear law and finite element modeling (FEM), in order to analyze unlubricated sliding wear observed in typical pin on disc tests. Such modeling was developed by using ABAQUS software with 3D deformable geometries and elastic-plastic material behavior for the contact surfaces. Numerical and experimental results were compared in terms of wear rate and friction coefficient. In the numerical simulation, the stress field distribution and changes in the surface profile across the worn track of the disc were analyzed [12]. Lamjahdy et al. measured the erosion rate of the brake disc and pad, depending on temperature changes and deformation by performing experiments and simulations at varying velocities and load conditions. Relationships between erosion rates and temperature changes for different brake disc velocities and load conditions were investigated [13]. Baldari et al. investigated the numerical simulation method of thermal load, contact stress, and wear coupling behavior between the brake disc and pad. And the wear behavior of the brake pad in both stress-wear coupled and emergency braking conditions was simulated respectively [14]. Zhang et al. based their study on the pin-disc wear test and the thermal-stress-wear sequential coupling method, considering influence of temperature on the friction pair material obtained in the evolution process of temperature field, stress field, and wear amount [15].

To study the friction and wear of the brake disc and pad, mathematical equations were used to calculate the wear depth. Because the change element of materials in

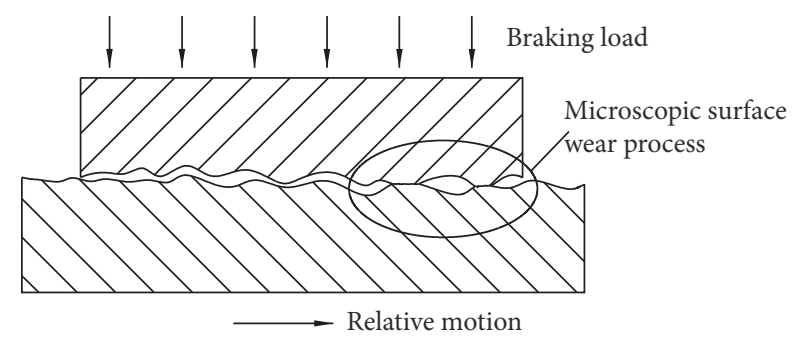

FIGURE 1: Diagram of the brake disc and pad wear.

finite element software is difficult to achieve, there is a certain limitation on the calculation of wear depth and the expression of wear profile by the software of ANSYS and ABAQUS. However, this paper calculates the wear depth by considering the factors affecting wear. Based on the tribological principle of the high-power disc brake, the friction and wear characteristics of the brake pad under high-speed and heavy-load conditions are studied, and the influence of braking parameters on the wear of the brake pad is analyzed.

\section{Analysis of Friction and Wear Mechanism of the Brake Pad}

The wear of the brake pad is the material damage, and it appears on the surface layer and subsurface layer caused by the thermomechanical coupling effect of the brake friction pair contact surface. It is essentially a complex dynamic changing process, as shown in Figure 1. Due to the large difference in hardness of the brake disc and pad, and the effect of the third body hard particles in the contact gap, the mainly wear type is abrasive wear. Abrasive wear can arise from the penetration and plowing out of material forming a surface of hard particles of the brake disc. Meanwhile, the adhesive wear occurs in high temperature regions. Adhesive wear occurs at the starting point for a wear process developing between two conforming friction surfaces. And the wear process cannot be generally characterized by a single type of event, except perhaps in the case of continuous severe wear [16].

The abrasive wear of the brake pad is mainly manifested as "plowing effect". The large hardness particles or microbulges penetrate and scrape the brake pad material; wear scar and abrasive dust are produced on the surface. The hard particles are pressed into the contact surface of the friction pair under load generating indentation, which increases the surface roughness of the friction pair, so that the contact peak of the microbulge is more likely to form a bond point, and the adhesive wear of the brake pad occurs. Especially under highspeed and heavy-load conditions, due to the large plastic deformation of the contact peak and high surface temperature, the phenomena of the shear in the bond point of fracture are caused by the relative sliding of the brake friction pair surface. A part of shedding materials becomes abrasive dust; others migrate from the brake surface to the disc surface to wear continually. 


\section{Mathematical Model of the Brake Pad Wear}

3.1. Calculation Model of the Brake Pad Wear. Due to extrusion and friction, the high temperature occurs on the friction pair at high-speed and heavy-load conditions, and there is serious wear on the friction contact. In 1953, the classical Archard wear theory was proposed by J. Archard [17]. The calculation equation is as follows:

$$
V=K \frac{P \cdot L}{H}
$$

where $V$ is the wear volume; $P$ is the normal force of the contact surface; $L$ is the relative sliding distance; $H$ is the material hardness; $K$ is the dimensionless wear coefficient. When the time increment is infinitesimal as $\mathrm{d} t$, (1) can be extended to the differential form:

$$
\frac{\mathrm{d} V}{\mathrm{~d} L}=K \cdot \frac{P_{t}}{H}
$$

where $\mathrm{d} V$ is the instantaneous wear volume increment, $\mathrm{d} L$ is the instantaneous sliding distance, and $P_{t}$ is the instantaneous normal interface contact force. Assuming that the wear depth increment on the microelement area $\Delta A$ is $\mathrm{d} h$ at time $\mathrm{d} t$, the instantaneous wear volume increment can be expressed as

$$
\mathrm{d} V=\Delta A \mathrm{~d} h
$$

where $\Delta A$ is the contact area of the brake disc and pad.

Substituting (3) into (2), and it can be expressed as

$$
\frac{\mathrm{d} h}{\mathrm{~d} L}=K \cdot \frac{p}{H}
$$

where $p$ is the contact pressure at the contact microelement area $\Delta A, p=P_{t} / \Delta A$. Since the relative sliding distance $L$ is the integral of the speed versus $v$ time $t,(4)$ can be rewritten as

$$
\mathrm{d} h=K \cdot \frac{p \cdot v}{H} \mathrm{~d} t
$$

where the independent variables $p$ and $v$ of theoretical calculation are usually constant.

However, under the actual high-speed and heavy-load braking conditions, the contact surface of any friction pair is rough. The actual contact area is related to the micromorphology of the contact surface. The stress value of every node on the contact interface is closely related to the wear depth and wear state of contact surface. The stress value changes with the wear depth change of each node on the contact surface, leading to the change wear degree of contact surface. Similarly, the high speed aggravates the friction of the contact pair, and a large amount of frictional heat is generated, and the friction material structure is changed, so does the hardness. The relationship between hardness and temperature of the material is as follows [18]:

$$
H=\text { const } \cdot \exp \left(\frac{\alpha}{\theta}\right)
$$

where $\alpha$ is a constant and $\theta$ is contact temperature.
Wear is affected by the hardness of the friction material, and the change of temperature could affect the hardness of the friction material. Especially under high-speed and heavyload braking conditions, the change of temperature is an important factor. Simultaneously, the virtual simulation software needs to calculate the relative contact speed, pressure, and temperature. However, the wear factors are considered distance, pressure, and material hardness in the original Archard wear calculation model. Therefore, the classical Archard wear model is no longer applicable for the simulated wear depth of a certain contact node. The Archard model is modified according to actual braking process. The contact pressure $p_{t}$, relative sliding velocity $v_{t}$, and interface contact temperature $\theta_{t}$ are considered as influencing factors. The specific correction equation is as follows:

$$
\mathrm{d} h_{t}=K \cdot \frac{p_{t} \cdot v_{t}}{\text { const } \cdot \exp \left(\alpha / \theta_{t}\right)} \mathrm{d} t
$$

The classical Archard wear equation is usually used to calculate the wear value of the relative rectilinear motion of two objects. However, when the brake disc and the brake pad of high-power disc brake are worn, the brake disc is in a state of rotation. The relative sliding speed of the contact interface is the tangential speed. Decompose the relative sliding tangential velocity:

$$
v_{t}=\omega_{t} \cdot r
$$

where $\omega_{t}$ is the relative sliding angular velocity and $r$ is the friction radius of the brake pad. Substituting (8) into (7), it can be expressed as

$$
\mathrm{d} h_{t}=K \cdot \frac{p_{t} \cdot \omega_{t}}{\text { const } \cdot \exp \left(\alpha / \theta_{t}\right)} \cdot r \mathrm{~d} t
$$

The integral of (9) for time $t$ in one braking time $\left(0, t_{0}\right)$ is expressed as

$$
h_{t}=K \cdot r \cdot \int_{0}^{t_{0}} \frac{p_{t} \cdot \omega_{t}}{\text { const } \cdot \exp \left(\alpha / \theta_{t}\right)} \mathrm{d} t
$$

Equation (10) is a continuous integral solution. However, finite element analysis requires step-by-step solution in virtual simulation. So, the solution of (10) is very difficult because the variable curve of the contact node is very complicated. For the convenience of calculation, the continuous wear value is discretized by the discrete method: a finite small-time increment $\Delta t$ is selected, and the corresponding wear depth increment is $\Delta h$. It is considered that the contact pressure $p_{t}$, relative sliding angular velocity $\omega_{t}$, and contact temperature $\theta_{t}$ do not change large during time increment $\Delta t$, and the instantaneous values of $p_{t}, \omega_{t}$, and $\theta_{t}$ are taken; then, Equation (9) becomes

$$
\Delta h_{t}=K \cdot r \cdot \frac{p_{t} \cdot \omega_{t}}{\text { const } \cdot \exp \left(\alpha / \theta_{t}\right)} \cdot \Delta t
$$

Since the wear of the brake interface is not evenly distributed between the brake disc and pad, the wear volume of the brake pad is solved by discrete method. 
As shown in Figure 2, assuming that the unit friction radius increment is $\Delta r$ within the time increment $\Delta t$, the unit microelement wear area can be expressed as

$$
\delta A_{t}=\left[\pi(r+\Delta r)^{2}-\pi r^{2}\right] \cdot \frac{\Delta \varphi}{2 \pi}
$$

where $\Delta \varphi$ is radians increment, $\Delta \varphi=\omega_{t} \cdot \Delta t$. The unit wear volume of the brake pad within the time increment $\Delta t$ is

$$
\Delta V_{t}=\delta A_{t} \cdot \Delta h_{t}
$$

Substituting (11) and (12) into (13), it can be expressed as

$$
\Delta V_{t}=K \cdot \frac{(\Delta r+2 r) \cdot r \cdot \Delta r}{2} \cdot \frac{p_{t} \cdot \omega_{t}^{2}}{\text { const } \cdot \exp \left(\alpha / \theta_{t}\right)} \cdot \Delta t^{2}
$$

When the disc brake is braking, the brake pad is considered as stationary state. There is wear on the brake pad, and the wear depth increment is $\Delta h$ in $\Delta t$ on the unit microelement contact area $\delta A$. The brake interface has different wear degrees with the change of the friction factor, and there is a feedback on the friction factor that the wear causes a change in the contact condition. The Euler integral method is used to calculate the wear by computer. The Euler method is a method of changing the differential equation of continuous variables to the difference equation of discrete variables. The numerical calculation is simple and easy, and the numerical convergence is good.

In time increment $\Delta t$, the contact pressure $p_{t}$, relative sliding angular velocity $\omega_{t}$, and contact temperature $\theta_{t}$ are assumed to be constant. The wear depth increment $\Delta h_{t}$ is obtained by Equation (11). The values of interface contact pressure $p_{t}$, relative sliding angular velocity $\omega_{t}$, and contact temperature $\theta_{t}$ after wear can be obtained by the finite element method. Then the wear depth $\Delta h_{t}$ can be calculated and the geometric mode is changed. Such loop iterations calculating the final accumulated wear value of the brake pad wear are obtained. The calculation method is as follows.

Assuming that the contact node of the brake disc and the brake pad is $i, i=1,2, \ldots, N$, and the integral step of the explicit Euler integral is $j, j=1,2, \ldots, M$, then the contact pressure is $p_{t}(i, j)$, the relative sliding angular velocity is $\omega_{t}(i, j)$, the contact temperature is $\theta_{t}(i, j)$, the wear depth is $\Delta h_{t}(i, j)$, and the wear volume is $\Delta V_{t}(i, j)$. The total wear depth $h(i, j)$ and volume $V(i, j)$ of braking at once of the brake pad can be expressed as

$$
\begin{gathered}
h(i, j)=\sum_{j=1}^{m} \Delta h_{t} \\
V(i, j)=\sum_{j=1}^{m} \Delta V_{t}
\end{gathered}
$$

Then the wear volume of the brake pad during the single braking of the disc brake can be expressed as

$$
V=\sum_{i=1}^{n} V(i, j)
$$

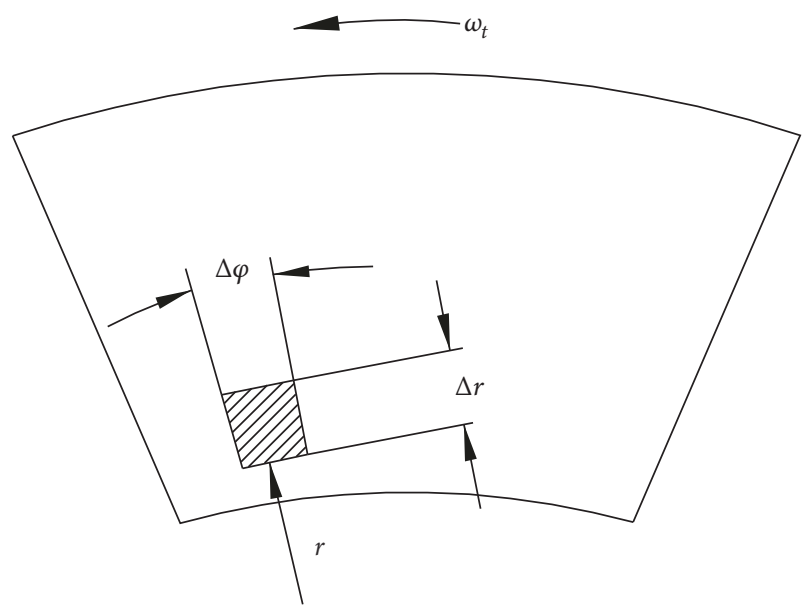

FIGURE 2: Calculation model of microelement wear area of the brake pad.

According to (17), the quantitative results of the brake pad wear after braking can be obtained. The process consists of two parts: one is to intercept and output the speed, stress, and temperature data in the wear stage from the time history curves of the contact point; the other is to divide the speed, stress, and temperature data and substitute these data into the equations to solve, as shown in Figure 3. DEFORM software has a special command to control the calculation of wear depth. Equation (5) can be added to the simulation program by compiling method to calculate the wear depth.

\subsection{Determination of Wear Direction on Brake Pad Node.} Affected by friction parameters, the surface roughness of contact surface after braking is different. There are two cases of the brake disc and the brake pad contact node: the boundary node at the edge of the contact surface and the nonboundary node located inside the contact surface. The wear direction of the nonboundary node can be determined by the normal of the contact node, and the wear direction of the boundary node is along the surface of the wear object. For the structured mesh, the connecting line direction of the nodes corresponding to their thickness direction is taken as the wear direction of point. As shown in Figure 4, the wear contact area is indicated by dashed line, the nodes 2, 3, 4, and 5 are in the contact area, node 1 is outside of contact area, nodes 3 and 4 belong to the nonboundary point, and nodes 2 and 5 belong to the boundary point. For node 3 , since its adjacent boundaries $b_{23}$ and $b_{34}$ are collinear, its normal direction is the common normal $\boldsymbol{n}_{3}$ of the two boundaries. For node 4 , since its two adjacent boundaries $b_{34}$ and $b_{45}$ are not collinear, the normal direction of node 4 is the vector sum direction of boundaries $b_{34}$ and $b_{45}$, which can be obtained by

$$
\boldsymbol{n}_{4}=\frac{\boldsymbol{n}_{4,1}+\boldsymbol{n}_{4.2}}{\left\|\boldsymbol{n}_{4,1}+\boldsymbol{n}_{4,2}\right\|}
$$

Node 2 belongs to the boundary node, its adjacent boundary $b_{23}$ is in contact state, and adjacent boundary $b_{12}$ is not in contact, so when wear occurs, node 2 moves along the direction $\boldsymbol{n}_{2}$ of the connecting line between node 2 and 


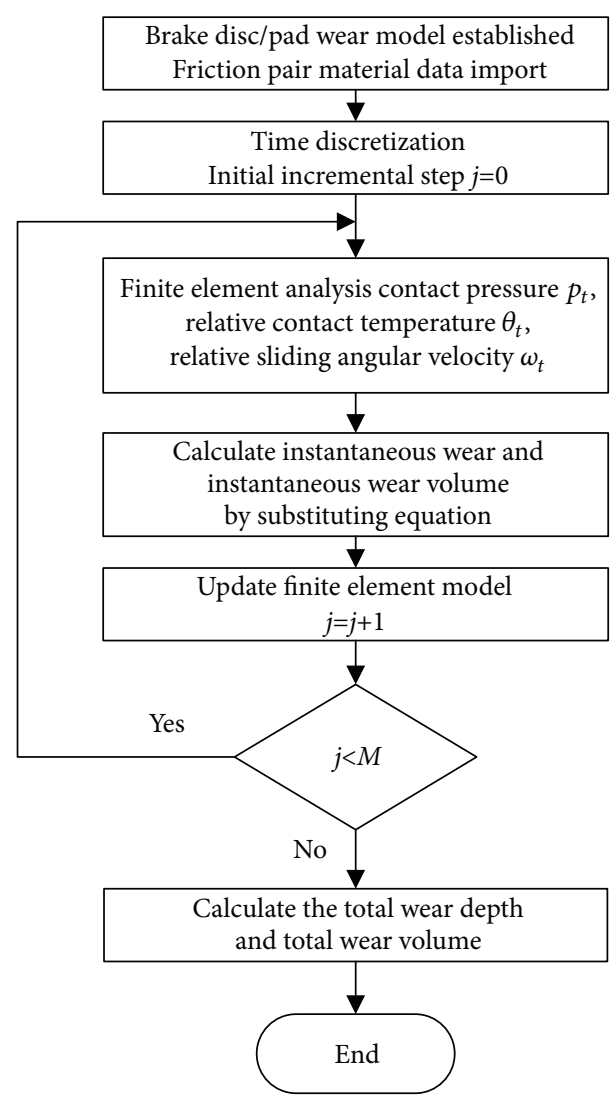

FIGURE 3: Flow chart of wear calculation.

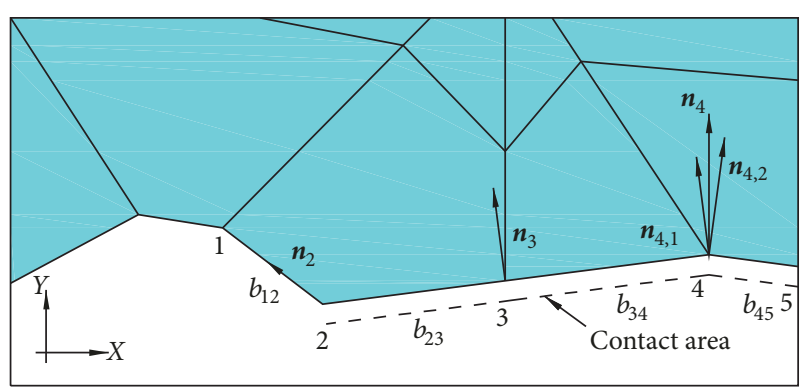

FIGURE 4: Diagram of the wear direction determination of the brake pad node.

node 1 . Therefore, through the analysis of the wear direction of the nodes, the mesh change process in the finite element analysis can be visually seen.

\section{Establishment of Finite Element Model for Brake Pad Wear}

To study the friction and wear characteristics of the brake pad during the braking process of high-power disc brake, it is necessary to establish a friction heat generation model and then the wear can be researched deeply. There are some assumptions as follows.

(1) The contact interface of the friction pair is an ideal plane.

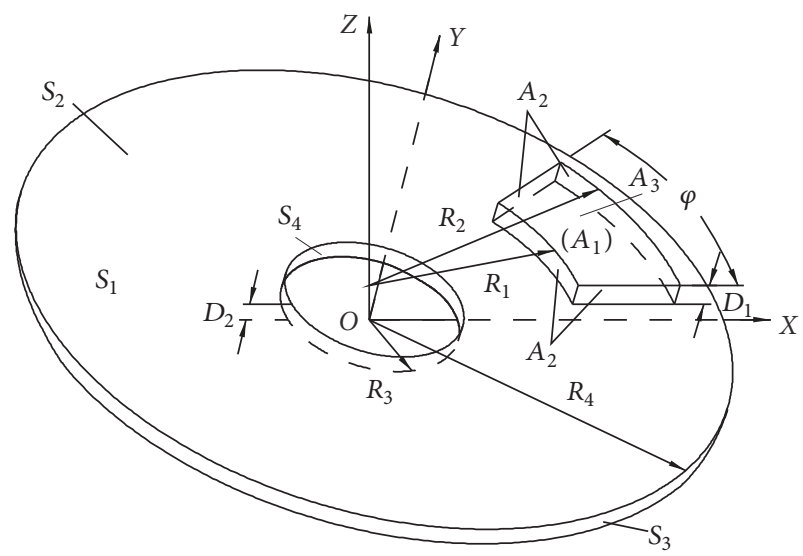

FIGURE 5: Diagram of the brake disc and the brake pad model.

(2) The friction condition accords with Coulomb's law and the friction factor is constant during the disc braking.

(3) The friction heat generated on the inner and outer sides of the brake pad is equal, so only one side of the brake disc is considered.

(4) The instantaneous temperature of the corresponding point on the contact area of the brake disc and the brake pad is equal.

(5) Assume that the pressure is evenly distributed on the brake pad.

(6) The material of the brake disc and the brake pad is an isotropic material. Due to the short emergency braking time, the thermal property parameters of the material do not change with temperature.

The model of brake disc and the brake pad is shown in Figure 5. $S_{1}, S_{2}, S_{3}$, and $S_{4}$ are the upper surface, the lower surface, the surface of the outer circle side, and the surface of the inner circle side, respectively; $A_{1}, A_{2}$, and $A_{3}$ are the wear surface of the brake pad, the side surface of the brake pad, and the upper surface of the brake pad, respectively; $R_{1}$ and $R_{2}$ are the inner and outer radius of the brake pad, respectively; $R_{3}$ and $R_{4}$ are the inner and outer circle radius of the brake disc, respectively; $D_{1}$ and $D_{2}$ indicate the thickness of the brake pad and the brake disc, respectively; $\varphi$ is the wrap angle of the brake pad. The values are shown in Table 1.

The results show that the stress-strain relationship of materials is greatly affected by factors of strain rate and temperature during plastic deformation. In order to simulating the braking process of the friction pair material accurately, a reasonable model is needed to describe the functional dynamic behavior of the material. When materials are subjected to dynamic loading conditions, a wide range of strains, strain rates, temperatures, and pressures may be experienced. Therefore, it is important that the effects of each variable be properly assessed, rather than assuming all distinguishing characteristics are due to strain rate alone [19].

The Johnson-Cook model can reflect the strain rate and temperature rise softening effect well and is currently widely used in finite element simulation. The Johnson-Cook model is a product relationship that describes the relationship 
TABLE 1: The parameters of brake disc and brake pad.

\begin{tabular}{lccccccc}
\hline Parameters & $R_{1} /(\mathrm{mm})$ & $R_{2} /(\mathrm{mm})$ & $R_{3} /(\mathrm{mm})$ & $R_{4} /(\mathrm{mm})$ & $D_{1} /(\mathrm{mm})$ & $D_{2} /(\mathrm{mm})$ & $\varphi$ \\
\hline Value & 245 & 365 & 100 & 400 & 26 & 26 & $36^{\circ}$ \\
\hline
\end{tabular}

between strain effect, strain rate effect, and temperature effect. The specific expression is [20]:

$$
\begin{aligned}
\sigma_{e}= & {\left[A+B\left(\varepsilon_{e}^{p}\right)^{n}\right]\left[1+C \ln \frac{\varepsilon_{e}^{p}}{\varepsilon_{o}}\right] } \\
& \cdot\left[1-\left(\frac{T-T_{\text {room }}}{T_{\text {melt }}-T_{\text {room }}}\right)^{m}\right]
\end{aligned}
$$

where $\sigma_{e}$ is the equivalent flow stress, $\varepsilon_{e}^{p} / \varepsilon_{0}$ is the relative equivalent plastic strain rate, $\varepsilon_{e}^{p}$ is the equivalent plastic strain, and $\varepsilon_{0}$ is reference plastic strain rate; the material constants $A, B, C, n$, and $m$ are the yield stress, hardening modulus, material strain rate strengthening parameter, hardening index, and thermal softening coefficient, respectively. $T_{\text {room }}$ is the room temperature and $T_{\text {melt }}$ is the melting point of the material. The specific parameters of the brake disc and the brake pad material are shown in Tables 2 and 3.

The solid model is built by Pro/E according to the model of brake disc and the brake pad, as shown in Figure 6(a). The finite element analysis of the solid model is then performed using the finite element analysis DEFORM software. The brake pad is rigid body and the brake disc is plastic. The mesh of the brake disc and the brake pad is meshed by the free mesh module. The number of elements of the brake disc is 58591, and the number of nodes is 14138; the number of elements of the brake pad is 7703, and the number of nodes is 1898 . The contact between the brake disc and the brake pad is set to point contact, as shown in Figure 6(b).

Based on the adaptive meshing technology of Deform-3D software, the deformation volume of the brake disc and the brake pad model is compensated automatically by using the tetrahedral mesh. The corresponding mesh encryption in the contact area of the brake friction pair ensures the calculation accuracy and improves the calculation efficiency. According to the high-speed and heavy-load conditions, the brake pad is considered as stationary, and the brake disc is rotated anticlockwise. The brake pad is clamped by the brake caliper, a fixed constraint in $x$ and $y$ directions is applied to the brake pad on $A_{2}$; the brake pad is subjected to the hydraulic pistonrod, assuming that the pressure is evenly distributed on the brake pad upper surface $A_{3}$. It can be expressed as

$$
\begin{aligned}
& \sigma_{z}=p \\
& u_{p x}=u_{p y}=0 \\
& \qquad\left(z=D_{1}, R_{1} \leq r \leq R_{2}\right)
\end{aligned}
$$

where $\sigma_{z}$ is the pressure of the brake pad in $z$ direction; $p$ is the initial braking load; $u_{p x}, u_{p y}$ are the displacements of the brake pad that may occur in $x$ and $y$ directions, as shown in Figure 7. The lower surface $S_{2}$ of the brake disc is axially fixedly constrained in $z$ direction. There can be expressed as

$$
u_{d z}=0 \quad\left(z=0, R_{3} \leq r \leq R_{4}\right)
$$

where $u_{d z}$ is the displacement of the brake disc in $z$ direction. Since the inner hole of the brake disc is connected to the brake shaft, a fixed constraint in the $z$-axis direction is applied to the inner circular side, and a rotational constraint of an angular velocity of $\omega_{t}$ is applied to simulate the decelerating motion of the brake disc. It can be expressed as

$$
\begin{aligned}
& \omega=\omega_{t} \\
& u_{d z}=0 \begin{array}{l}
\quad \\
\quad\left(0 \leq z \leq D_{2}, \quad r=R_{3}\right)
\end{array}
\end{aligned}
$$

where $\omega$ is the rotational angular velocity of the brake disc and $u_{d z}$ is the displacement of the brake disc in $z$ direction, as shown in Figure 8.

According to assumption (6), the heat exchange coefficient of the brake disc and the brake pad interface selected $45 \mathrm{~N} / \mathrm{sec} / \mathrm{mm} / \mathrm{C}$ as a constant. The ambient temperature is $20^{\circ} \mathrm{C}$; the shear failure model and the tensile failure model are selected. And the wear Equation (5) is used to calculate the wear depth of the brake pad by program, based on the Archard wear correction equation. Braking load of $13000 \mathrm{~N}$, initial braking speed of $1000 \mathrm{r} / \mathrm{min}$, and braking time of $24.98 \mathrm{~s}$ are selected, and the finite element analysis is carried out.

\section{Analysis of Simulation Results of the Brake Pad Wear}

5.1. Simulation Analysis of the Brake Pad Wear in Single Braking. The wear process of the brake pad is an accumulation, and the results of wear on the surface of the brake pad under different steps are shown in Figure 9. The brake pad wear is mainly affected by the friction force. According to the friction direction of the brake pad in Figure 9(a), the left edge of the brake pad is defined as a friction inlet, and the right edge is defined as a friction outlet.

According to the wear nephogram of the brake pad, it can be seen that the wear distribution of the brake pad during the braking process is uneven, and the wear area changes with time. Throughout the whole wear process, there is a significant difference in the wear degree between the friction inlet and the friction outlet of the brake pad. Both ends of the edge of the brake pad are affected seriously by tensile stress and compressive stress on the friction inlet and outlet, respectively. Due to the rotary motion of the brake disc, there is a linear speed difference in the radial direction of the brake disc, and the outer edge of the brake pad has a large line speed and wear, while the inner edge wear of the brake pad is weak.

The data points $P_{1}-P_{15}$ uniformly distributed on the brake pad are extracted from Figure 10, and the simulated wear depth of points is extracted according to the simulation results of the data points. The wear depth curves of the brake track point are drawn as shown in Figure 11. The wear 
TABLE 2: Material parameters of the brake disc and the brake pad.

\begin{tabular}{lcccccc}
\hline $\begin{array}{l}\text { Material } \\
\text { parameters }\end{array}$ & $\begin{array}{c}\text { Density/ } \\
\left(\mathrm{kg} / \mathrm{m}^{3}\right)\end{array}$ & $\begin{array}{c}\text { Thermal } \\
\text { conductivity/ } \\
{[\mathrm{W} /(\mathrm{m} \cdot \mathrm{K})]}\end{array}$ & $\begin{array}{c}\text { Elastic } \\
\text { modulus/ } \\
(\mathrm{GPa})\end{array}$ & $\begin{array}{c}\text { Poisson's } \\
\text { ratio }\end{array}$ & $\begin{array}{c}\text { Linear expansion } \\
\text { coefficient/ } \\
\left(10^{-5}\right)\end{array}$ & $\begin{array}{c}\text { Specific heat capacity/ } \\
{[\mathrm{J} /(\mathrm{kg} \cdot \mathrm{K})]}\end{array}$ \\
\hline Brake pad & 5250 & 400 & 180 & 0.3 & 1.11 & 436 \\
Brake disc & 7850 & 48 & 204 & 0.31 & 0.95 & 480 \\
\hline
\end{tabular}

TABLE 3: Material constitutive parameters of the brake disc and the brake pad.

\begin{tabular}{lccccc}
\hline Constitutive parameters & $A$ & $B$ & $C$ & $n$ & $m$ \\
\hline Value & 90 & 292 & 0.025 & 0.31 & 1.09 \\
\hline
\end{tabular}

depth is represented by points $P_{1}-P_{15}$ of the curves from the friction inlet to the friction outlet. To clearly describe the wear condition of the brake pad, let points $P_{1}, P_{6}$, and $P_{11}$ belong to the friction inlet region, and points $P_{5}, P_{10}$, and $P_{15}$ belong to the friction outlet region point; the others belong to the friction intermediate region. The wear of the friction inlet of the brake pad is composed of two parts. One part of wear is caused by extrusion caused by the relative movement of the brake disc and the brake pad. The elements of the brake pad and the brake disc are squeezed against each other, so that the surface of the brake disc is not flat due to deformation of the mesh element. The other part is the effect of the braking friction on the rough surface. There will be rough peaks on the surface of the deformation of the brake disc. And the rough peaks are squeezed during the relative movement, causing the material to undergo shear deformation and wear. The combination of the two parts aggravates the deformation of the material. The interface contact pressure increases and the local temperature rises, so that the wear is severe. And the wear depth at the edge of friction inlet is relatively large. Because the friction intermediate region is far away from the friction edge and the pressing force is small, the material deformation is not obvious, and the friction heat is low, and then the wear degree is small. In the middle area of the brake pad, the wear depth increases slowly firstly and then rises sharply with the change of temperature and pressure. Due to the heat conduction of the brake disc, the friction outlet temperature of the brake pad is high, and the wear is mainly adhesive wear. The friction material transfers adhesively so that the friction surface is rough.

The severe wear of the brake pad during braking only occurs in local areas. Figure 12 shows the three-dimensional wear profile of the brake pad at the $1000^{\text {th }}$ step. As shown in Figure 12(a), the brake pad is serious at the edge of the friction outlet; at this time the maximum wear depth is $0.0684 \mathrm{~mm}$. The severe wear area accounts for a small part of the total area of the brake pad, and the wear depth of other part area is low. The surface topography does not change obviously. To clearly analyze the change of surface topography, half of the maximum wear depth $0.0137 \mathrm{~mm}$, mesoscopic size of wear depth $0.005 \mathrm{~mm}$ and $0.001 \mathrm{~mm}$ of this time are selected respectively to limit the maximum wear. And the surface topography is output and observed from different wear levels as half of the maximum wear depth $0.0137 \mathrm{~mm}$, mesoscopic size of wear depth $0.005 \mathrm{~mm}$ and $0.001 \mathrm{~mm}$. When the maximum wear depth is limited to $0.0137 \mathrm{~mm}$, the wear depth of the friction outlet of the brake pad changes obviously. This is because there is no material back up at the friction outlet. The material is easily broken and fractured during braking, causing severe wear as shown in Figure 12(b). The closer it is to the friction outlet, the greater the wear degree is. It can also be seen from Figures 12(c) and 12(d) that the surface roughness is large from the friction outlet to the intermediate area, the local wear is severely at the friction outlet.

Braking parameters are the keys to ensuring brake safety on the premise of braking efficiency. Proper selecting of braking parameters not only saves energy, but also saves material losses caused by wear. Therefore, it is necessary to study the influence of braking parameters on the brake pad wear. The braking load and initial braking speed play important roles in the brake pad wear during braking process. The single variable method is used to compare the brake pad wear under different working conditions.

5.2. Influence of Braking Load on the Brake Pad Wear. Under the conditions of initial braking speed is $1000 \mathrm{r} / \mathrm{min}$ and friction coefficient of contact surface is 0.3 , the brake pad wear with brake loads of $13000 \mathrm{~N}, 17000 \mathrm{~N}$, and $21000 \mathrm{~N}$ is analyzed by finite element method. The nephogram of the brake pad at the end of braking is shown in Figure 13. According to the simulation results, the maximum wear depth of the corresponding steps can be extracted. Figure 14 shows the number of simulation steps is as the horizontal axis, and the maximum wear depth is as the vertical axis and the comparison curves of the maximum brake pad wear depth under different braking loads.

The wear distribution of the brake pad under different loads is basically the same. The maximum wear depth is $6.4 \times$ $10^{-2} \mathrm{~mm}$ when the number of simulation steps is the $1000^{\text {th }}$ step and the braking load is $13000 \mathrm{~N}$. The maximum wear depth is $7.34 \times 10^{-2} \mathrm{~mm}$ when the braking load is $17000 \mathrm{~N}$, and the maximum wear depth is $8.09 \times 10^{-2} \mathrm{~mm}$ when the braking load is $21000 \mathrm{~N}$. Friction always occurs at a part of the contact peak, and the number of contacts point and the size of each contact point increase with load. Therefore, the friction is affected by load through the contact area size and deformation state. And then the friction affects the wear of the material. The increase of braking load directly increases the contact pressure of the friction pair. The interface contact area becomes large, forcing the friction material to deform and aggravating the wear of the brake pad. Figure 14 shows the change in the amount of the brake pad wear under different 


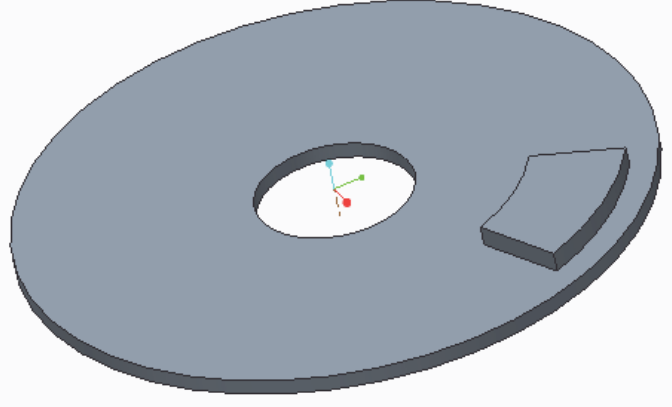

(a) Solid model

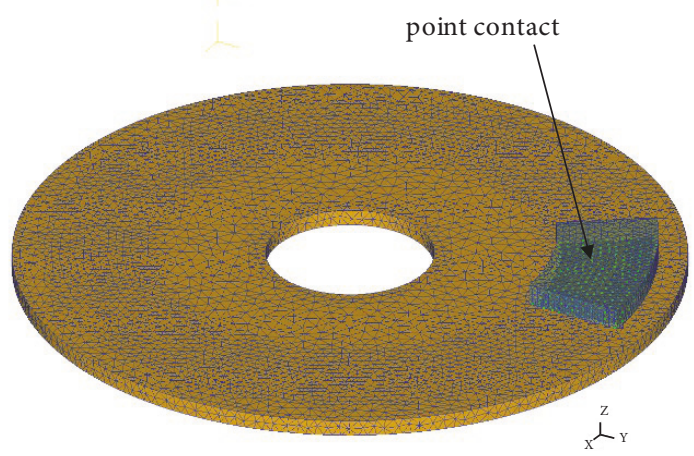

(b) Grid model

FIGURE 6: Finite element model of brake disc and brake pad.

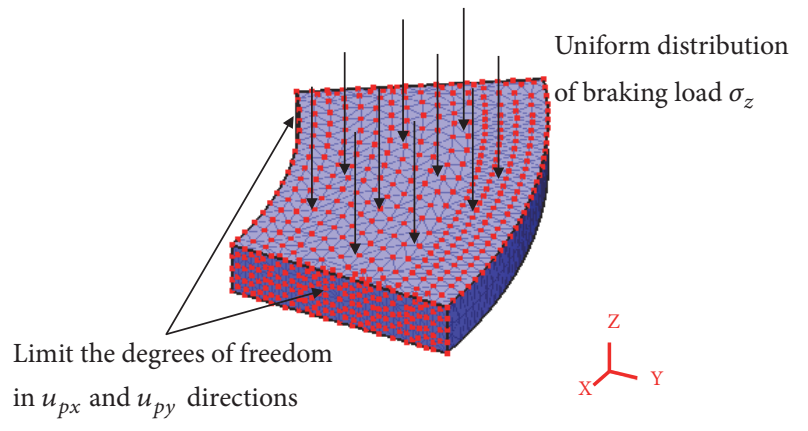

FIGURE 7: Diagram of the brake pad boundary conditions.

braking loads. In the $200^{\text {th }}$ step of the early wear stage of the brake pad, the wear is in a sharp rise stage, and the effect of braking load on the wear is small. In the later wear stage from the $200^{\text {th }}$ step to the $1000^{\text {th }}$ step, the slope of the wear curve remains basically the same, and the accumulation of wear increases steadily. However, the maximum amount of wear between the different loads is obviously different and the accumulation of wear difference becomes large.

\subsection{Influence of Initial Braking Speed on the Brake Pad Wear.} It is planned to the braking load $17000 \mathrm{~N}$ and the friction coefficient 0.3 of the contact surface. Compared with the brake pad wear degree of initial braking speeds of $800 \mathrm{r} / \mathrm{min}$, $1000 \mathrm{r} / \mathrm{min}$, and $1200 \mathrm{r} / \mathrm{min}$, respectively, the distribution trend is shown in Figure 15. In order to analyze the wear change of the brake pad accurately, the brake pad wear simulation results can be obtained through postprocessing. The comparison curves of the maximum wear depth of the brake pad under different initial braking speeds are shown in Figure 16.

Figure 15 shows the wear distribution of the brake pad at different initial braking speeds at the $1000^{\text {th }}$ step. The maximum wear depth at the initial braking speed of $800 \mathrm{r} / \mathrm{min}$ is $6.71 \times 10^{-2} \mathrm{~mm}$, and the radial wear of the brake pad is unevenly transitioned from the inner circle region to the outer circle region. When the initial braking speed is
$1000 \mathrm{r} / \mathrm{min}$, the maximum wear depth is $7.34 \times 10^{-2} \mathrm{~mm}$. When the initial braking speed is $1200 \mathrm{r} / \mathrm{min}$, the radial wear of the brake pad changes uniformly, and the maximum wear depth is $8.25 \times 10^{-2} \mathrm{~mm}$. Generally, the surface layer heating, deformation, chemical changes, and wear are caused by the relative sliding speed. The relative sliding speed affects the friction force through the temperature condition of the brake pad. The change of heating and temperature can change the property of the surface layer and the surface interaction and failure conditions during friction. Therefore, the wear degree of the brake pad is different. The initial braking speed determines the relative sliding speed during the braking process. Large relative sliding speed increases the extrusion force and shear force of the rough surface during friction, leading to the increase of strain, stress value, and more serious wear of the brake pad. In Figure 16, the horizontal axis represents the number of simulation steps, and the vertical axis represents the maximum amount of wear. The wear curves show in the increase degree of maximum wear of the brake pad. The maximum wear depth at the initial braking speed of $1200 \mathrm{r} / \mathrm{min}$ is generally greater than that at the initial braking speed of $1000 \mathrm{r} / \mathrm{min}$ during braking. The maximum wear depth at the initial braking speed of $1000 \mathrm{r} / \mathrm{min}$ is also greater than that at the initial braking speed of $800 \mathrm{r} / \mathrm{min}$. The difference of the maximum wear depth of the three conditions is relatively small in the early wear stage. The wear difference is large in the later wear stage, and the difference value is basically the same.

\section{Experimental Verification}

6.1. Experimental Procedure. The wear test of the brake pad is carried out in a high-power wind turbine brake, as shown in the Figure 17. The disc brake can be used for the braking performance test of high-speed and heavy-load conditions for high-power disc brake and could meet the requirements of the braking wear test in the emergency conditions. The brake disc is interconnected to the brake shaft by a keyway. There are some assumptions as follows. (1) When the drive shaft and the inertia flywheel are rotated to the set speed of $1000 \mathrm{r} / \mathrm{min}$, 


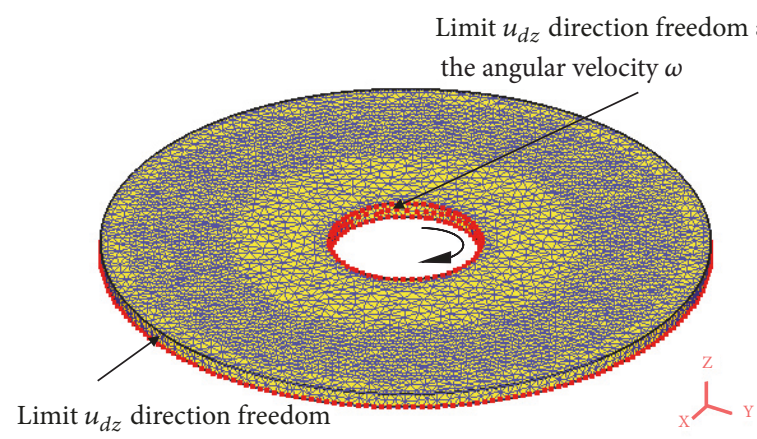

FIGURE 8: Diagram of the brake disc boundary conditions.

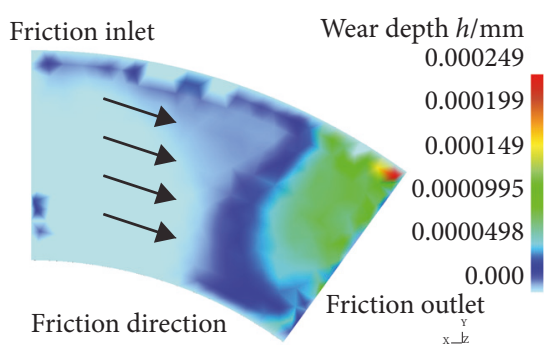

(a) Step 1

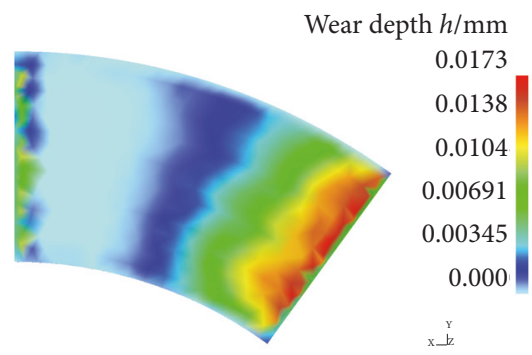

(c) Step 200

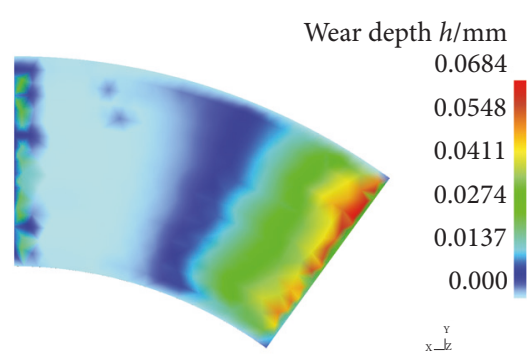

(e) Step 800

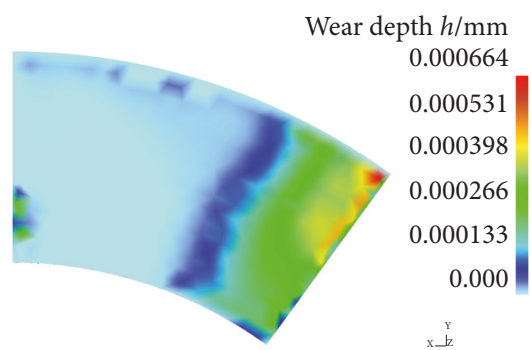

(b) Step 10

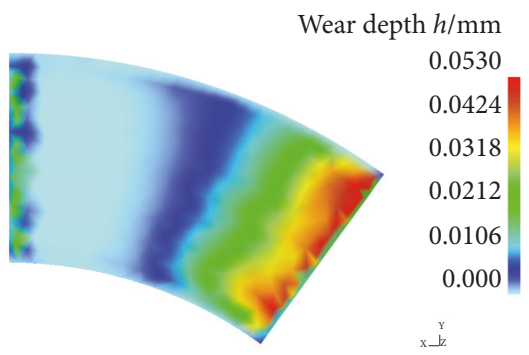

(d) Step 500

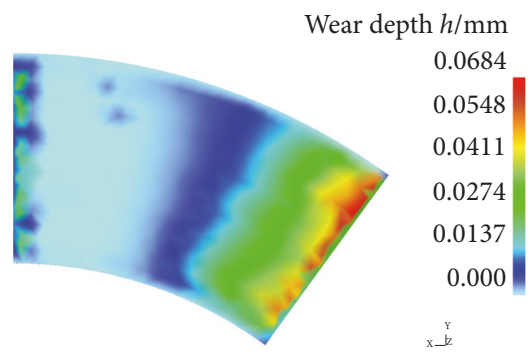

(f) Step 1000

Figure 9: Nephogram of the brake pad wear depth.

the brake disc is released from the control of the drive motor and the brake pad is loaded by hydraulic pressure. (2) Friction is generated to achieve braking of the brake disc due to the relative sliding of the brake disc and the brake pad.

The brake pad material is made of copper-based powder metallurgy and the brake disc material is Q345B. The material properties have the same characteristics in Table 1 . The size and installation position of the brake disc and brake pad on the test machine are consistent with the model of brake disc and the brake pad with Figure 5. Test condition parameters are shown in Table 4.

Besides, in order to remove surface impurities, the surface of the brake disc and the brake pad need to be polished with sandpaper. There is also a micrometer for measuring 
TABLE 4: Test condition parameters.

\begin{tabular}{|c|c|c|c|c|c|c|}
\hline $\begin{array}{l}\text { Number of } \\
\text { friction faces }\end{array}$ & $\begin{array}{c}\text { Moment of } \\
\text { inertia/ }\left(\mathrm{kg} \cdot \mathrm{m}^{2}\right)\end{array}$ & $\begin{array}{c}\text { Ambient } \\
\text { temperature/ }\left({ }^{\circ} \mathrm{C}\right)\end{array}$ & $\begin{array}{c}\text { Atmospheric } \\
\text { intensity of } \\
\text { pressure/ (KPa) }\end{array}$ & $\begin{array}{l}\text { Relative } \\
\text { humidity }\end{array}$ & $\begin{array}{c}\text { Braking } \\
\text { pressure/ (N) }\end{array}$ & $\begin{array}{l}\text { Initial braking } \\
\text { speed/ (r/min) }\end{array}$ \\
\hline 1 & 700 & 20 & 101.3 & $37 \%$ & 13000 & 1000 \\
\hline
\end{tabular}

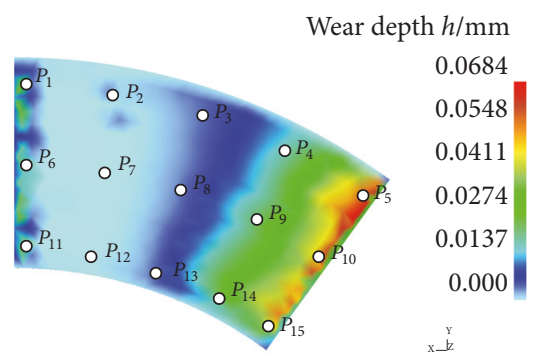

FIGURE 10: Nephogram of the brake pad point tracking.

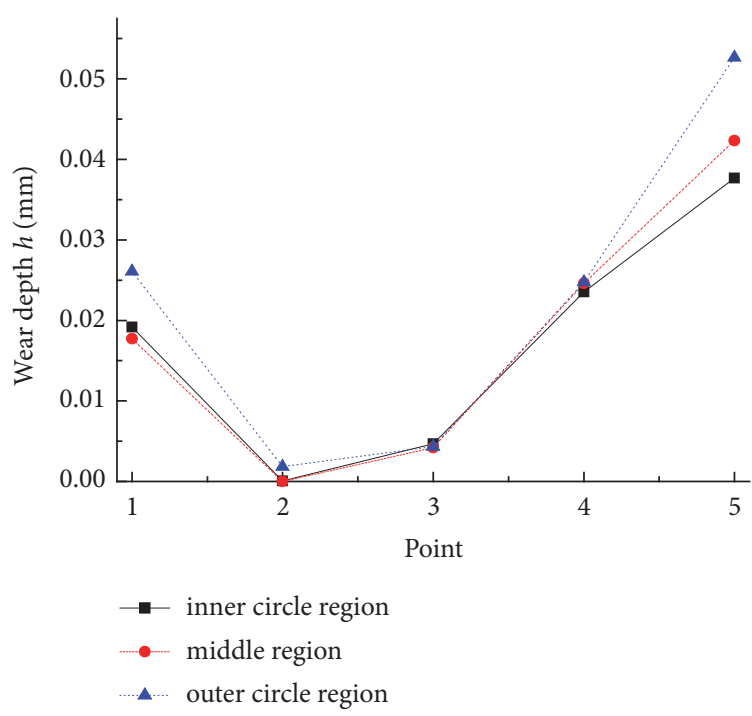

FIGURE 11: Chart of the brake pad point tracking wear curves.

the different positions of the brake disc and the brake pad to ensure that the two surfaces are smooth enough to produce a good fit.

6.2. Results and Discussion. In order to verify the accuracy of simulation, the finite element wear depth results (Figure 10) are compared with the actual wear of the brake pad under the same operating conditions in experiments (Figure 18). Points $Q_{1}-Q_{15}$ at the corresponding positions on Figure 18 are measured by $1: 1000 \mathrm{~mm}$ digital dial gauge, and each position is measured three times to take the average values as the wear depth of points $Q_{1}-Q_{15}$. The results comparison of simulation and experimental wear depth are drawn as shown in Figure 19.

In the actual friction and wear process, the friction heat of the surface material rises quickly with the braking process. High temperature reduces the hardness of the material, promoting the deformation of the brake disc and the brake pad. The copper-based material will be softened with the temperature rising rapidly. Softening of the copperbased material leads to a decrease in particle holding ability, increasing the surface wear of the brake pad, as shown in Figure 18. Figure 19 shows the wear depth in the simulation and experimental results of the brake pad. The $x$ axis represents the lateral distribution of the brake pad, and the $y$ axis represents the longitudinal distribution. Comparing the simulated and experimental results of wear depth, although the values between the brake disc and the brake pad are very different, the wear distribution trend at different locations is still roughly the same. The main reason for the difference between the two values is the difference of braking time. In simulations, due to the limited number of simulation steps, the simulated braking time is much shorter. But in experiments, to facilitate the observation of wear state, the actual braking time is long. Comparing the longitudinal distribution of the simulated and experimental results, the outer circle region and inner circle region of the friction inlet wear value are larger than those of the middle region results. This is because stress concentration occurs without backing up by the side material in the outer circle region and inner circle region. The wear depth at the friction outlet increases from the inner circle region to the outer circle region, because the outer circle region has a higher frictional line speed than the inner circle region, and the temperature of the outer circle region is high, the corresponding wear is also large. Comparing the lateral distribution of the simulation and experimental wear, there is large wear at the friction inlet. The wear shows as a rising trend from the intermediate area to the wear outlet. Due to the short simulation time, the brake pad wear depth far away from the wear outlet is small, and the difference of the wear in the middle area is large. However, the surface wear is relatively uniform and the wear difference is small after a period of wear.

\section{Conclusions}

This work has focused on an investigation and comparison of the wear progression and wear mechanism of the brake pad in the high-speed and heavy-load conditions. The followings are the key conclusions drawn from this study.

(1) The wear of the brake pad is a cumulative process, and the wear depth of the brake pad increases quickly and then slowly. The friction inlet and outlet edge regions of brake pad are extruded during braking, which is severely worn compared to the middle of the brake pad. Compared with the experimental results, it is the same trend that the proposed simulation model is in different parts. So, the model validity is verified. 


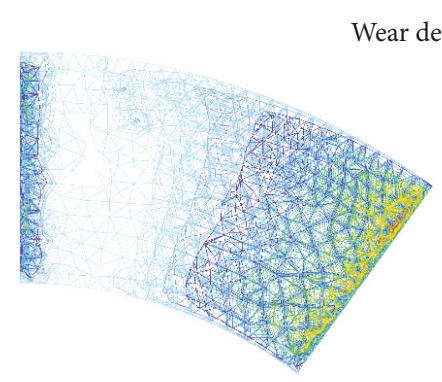

(a) $0.0684 \mathrm{~mm}$

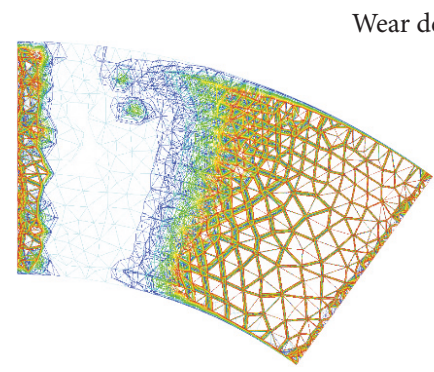

(c) $0.005 \mathrm{~mm}$

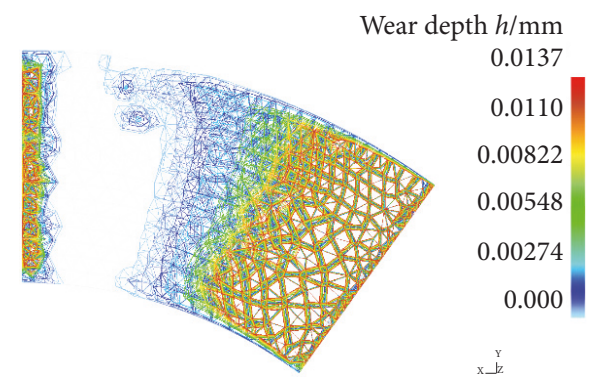

(b) $0.0137 \mathrm{~mm}$
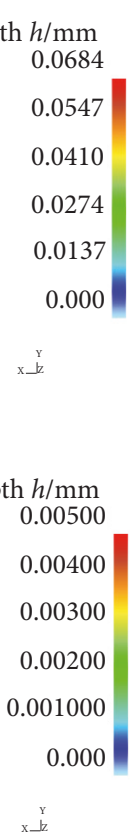

$\underset{x+y}{x}$

FIGURE 12: Nephogram of wear profile of the brake pad at different maximum wear depths.

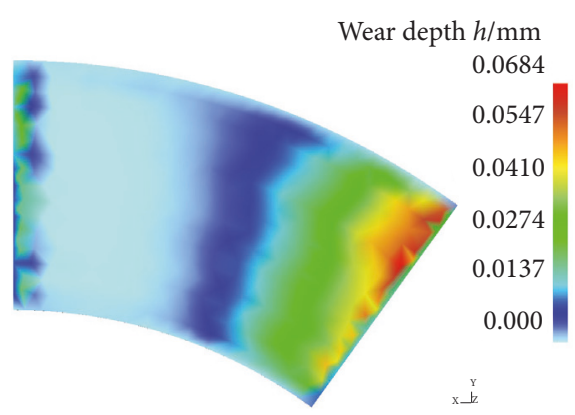

(a) Braking load $13000 \mathrm{~N}$

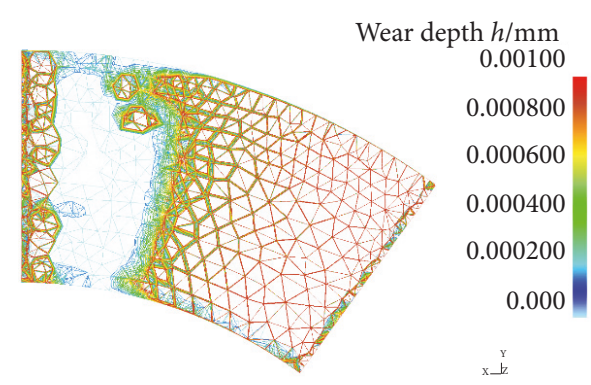

(d) $0.001 \mathrm{~mm}$ 


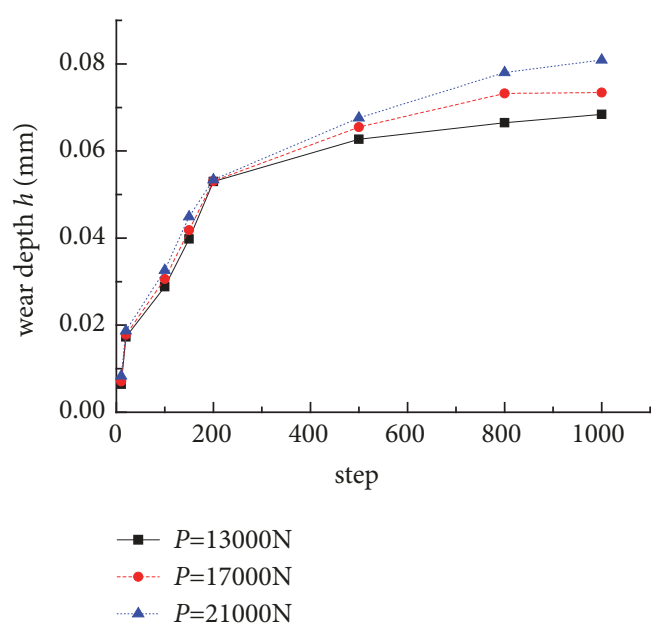

FIGURE 14: Chart of the brake pad wear depth with different braking loads.

speed is $1200 \mathrm{r} / \mathrm{min}$, and the maximum wear depth is $8.25 \times$ $10^{-2} \mathrm{~mm}$.

\section{Glossary}

V: $\quad$ The wear volume

P: The normal force of the contact surface

L: $\quad$ The relative sliding distance

$H: \quad$ The material hardness

$K: \quad$ The dimensionless wear coefficient

$\Delta A: \quad$ The contact area of the brake disc and pad

$\mathrm{d} t: \quad$ The time increment

$\mathrm{d} V: \quad$ The instantaneous wear volume increment

$\mathrm{d} L: \quad$ The instantaneous sliding distance

$P_{t}$ : The instantaneous normal interface contact force

$p: \quad$ The contact pressure at the contact microelement area

$v$ : $\quad$ The relative sliding velocity

$\alpha: \quad$ A constant

$\theta: \quad$ Interface contact temperature

$\omega_{t}$ : The relative sliding angular velocity

$r: \quad$ The friction radius of the brake pad

$\Delta t: \quad$ A finite small-time increment

$\Delta h: \quad$ The corresponding wear depth increment

$p_{t}: \quad$ The contact pressure

$\theta_{t}: \quad$ Contact temperature

$\Delta r: \quad$ The unit friction radius increment

$\Delta \varphi: \quad$ Radians increment

$p_{t}(i, j):$ The contact pressure

$\omega_{t}(i, j)$ : The relative sliding angular velocity

$\theta_{t}(i, j)$ : The contact temperature

$\Delta h_{t}(i, j):$ The wear depth

$\Delta V_{t}(i, j)$ : The wear volume

$S_{1}$ : $\quad$ The upper surface

$S_{2}$ : The lower surface

$S_{3}$ : The surface of the outer circle side

$S_{4}$ : $\quad$ The surface of the inner circle side

$A_{1}$ : The wear surface of the brake pad
$A_{2}: \quad$ The side surface of the brake pad

$A_{3}$ : The upper surface of the brake pad

$R_{1}$ : The inner radius of the brake pad

$R_{2}$ : The outer radius of the brake pad

$R_{3}$ : The inner circle radius of the brake disc

$R_{4}$ : The outer circle radius of the brake disc

$D_{1}$ : The thickness of the brake pad

$D_{2}$ : The thickness of the brake disc

$\varphi$ : The wrap angle of the brake pad

$\sigma_{e}: \quad$ The equivalent flow stress

$\varepsilon_{e}^{p} / \varepsilon_{0}$ : The relative equivalent plastic strain rate

$\varepsilon_{e}^{p}: \quad$ The equivalent plastic strain

$\varepsilon_{0}$ : Reference plastic strain rate

$A$ : The yield stress

$B$ : Hardening modulus

$C$ : Material strain rate strengthening parameter

$n$ : Hardening index

$m$ : Thermal softening coefficient

$\sigma_{z}: \quad$ The pressure of the brake pad in $z$ direction

$p: \quad$ The initial braking load

$u$ : The displacements of the brake pad that may occur in $x$ direction

$u$ : The displacements of the brake pad that may occur in $y$ direction

$u_{d z}$ : The displacement of the brake disc in $z$ direction

$\omega$ : A rotational constraint of an angular velocity.

\section{Data Availability}

No data were used to support this study.

\section{Conflicts of Interest}

The authors declare that there are no conflicts of interest regarding the publication of this paper. 


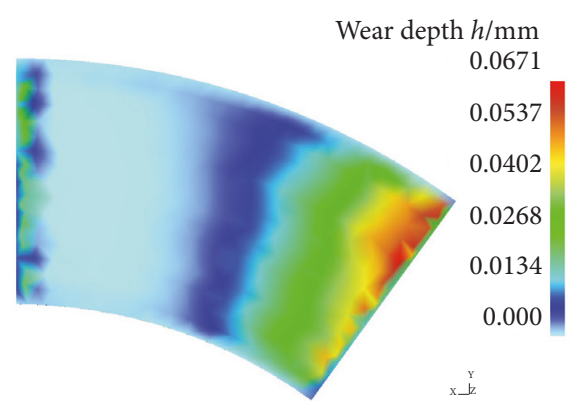

(a) Initial braking speed $800 \mathrm{r} / \mathrm{min}$

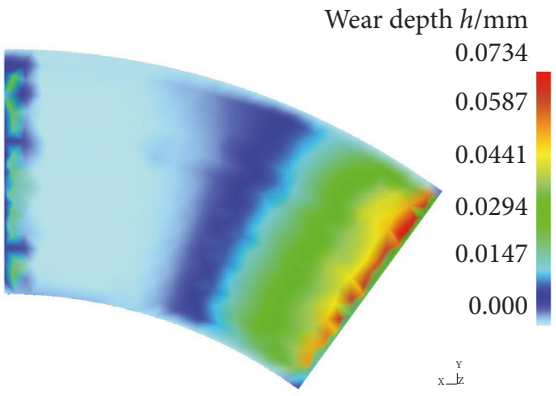

(b) Initial braking speed $1000 \mathrm{r} / \mathrm{min}$

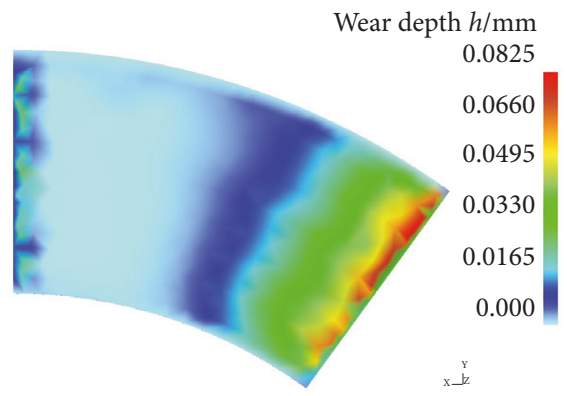

(c) Initial braking speed 1200r/min

FIGURE 15: Nephogram of the brake pad wear with different initial braking speeds.

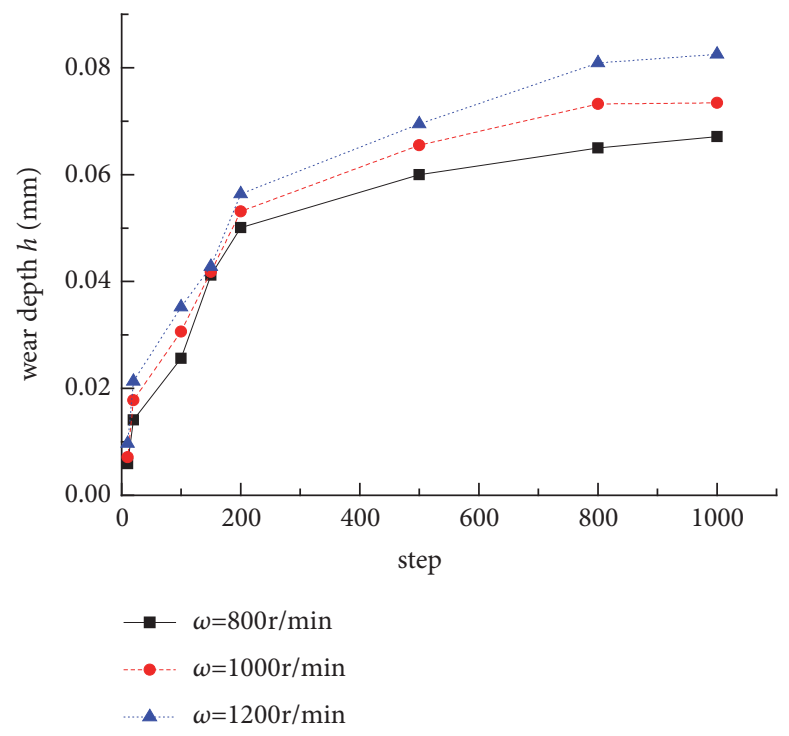

FIGURE 16: Chart of the brake pad wear depth with different initial braking speeds.

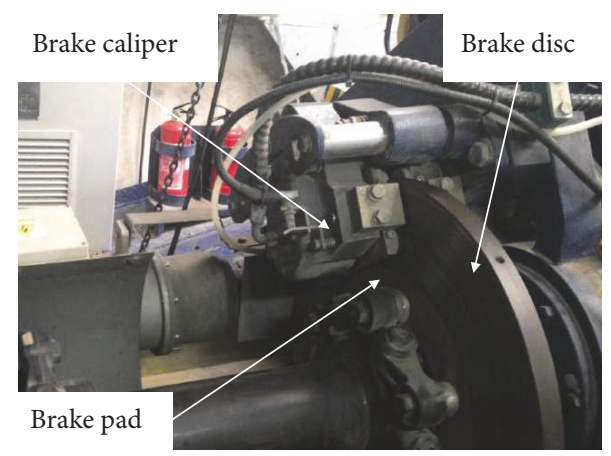

FIGURE 17: High-power wind turbine brake. 


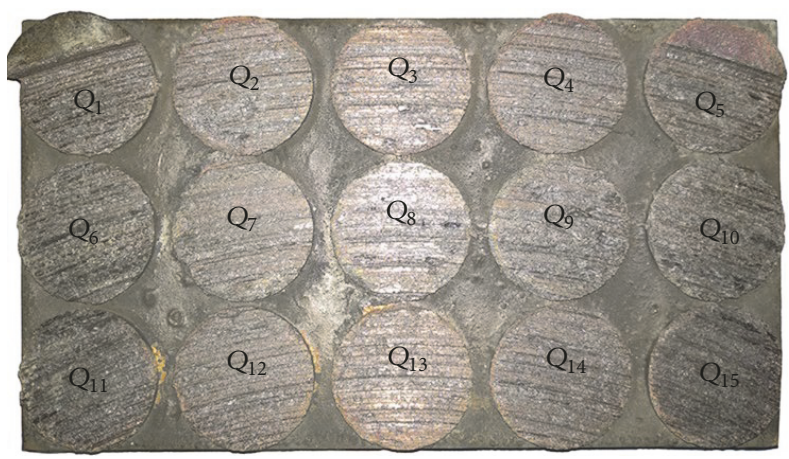

FIGURE 18: Nephogram of the brake pad experimental measuring point position.

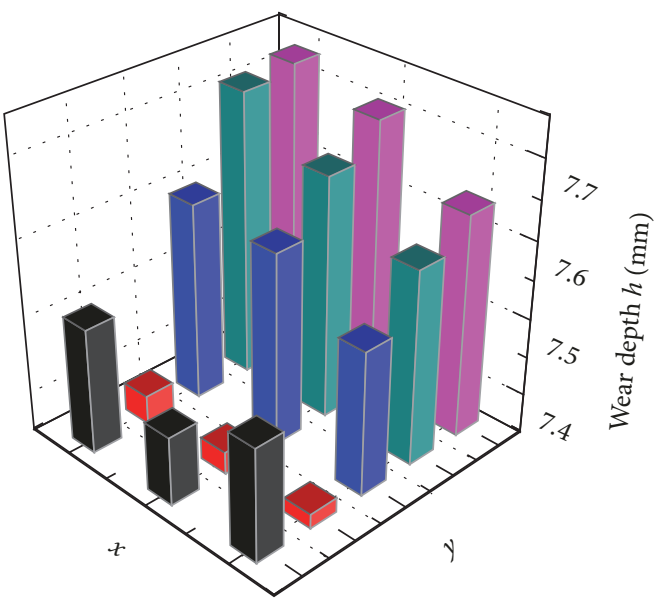

(a) Simulation wear depth

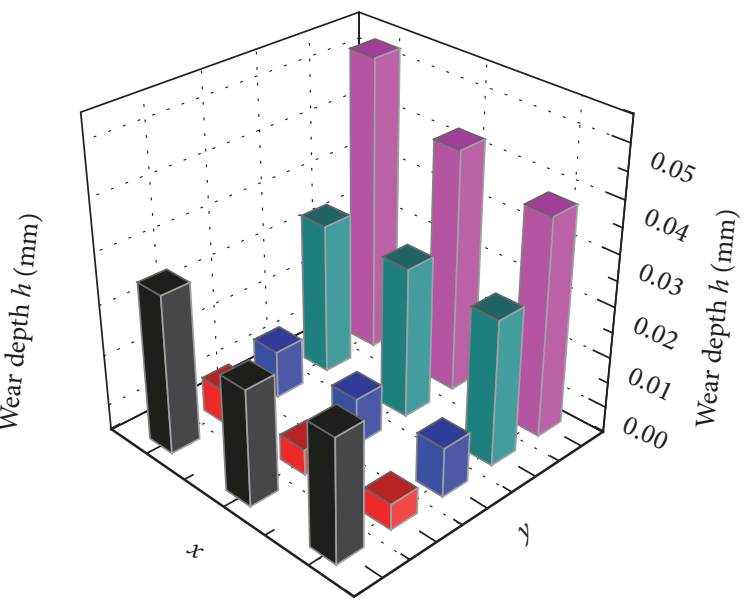

(b) Experimental wear depth

FIGURE 19: Comparison of the brake pad simulation and experimental wear depth.

\section{Acknowledgments}

The authors gratefully acknowledge the financial support of National Natural Science Foundation of China (No. 51675075) and Innovative Talents Program of Colleges and Universities in Liaoning Province (No. LR2018048).

\section{References}

[1] P. Zagrodzki, "Analysis of thermomechanical phenomena in multidisc clutches and brakes," Wear, vol. 140, no. 2, pp. 291308, 1990.

[2] K. Lee and R. B. Dinwiddie, "Conditions of frictional contact in disk brakes and their effects on Brake Judder," SAE Technical Papers, 1998.

[3] K. Friedrich, J. Flöck, K. Váradi, and Z. Néder, "Numerical and finite element contact and thermal analysis of real compositesteel surfaces in sliding contact," Wear, vol. s 225-229, no. 4, pp. 368-379, 1999.

[4] V. Gupta, G. T. Hahn, P. C. Bastias, and C. A. Rubin, “Thermalmechanical modelling of the rolling-plus-sliding with frictional heating of a locomotive wheel," Journal of Engineering for Industry, vol. 117, no. 3, pp. 418-422, 1995.

[5] A. Belhocine, "Thermomechanical behaviour of dry contacts in disc brake rotor with a grey cast iron composition," Transactions of the Indian Institute of Metals, vol. 17, no. 2, pp. 231-238, 2013.
[6] J. Choi and I. Lee, "Finite element analysis of transient thermoelastic behaviors in disk brakes," Wear, vol. 257, no. 1-2, pp. 47-58, 2004.

[7] A. A. Yevtushenko and P. Grzes, "3D FE model of frictional heating and wear with a mutual influence of the sliding velocity and temperature in a disc brake," International Communications in Heat and Mass Transfer, vol. 62, no. 3, pp. 37-44, 2015.

[8] V. P. Sergienko, M. Y. Tseluev, V. I. Kolesnikov, A. P. Sychev, V. A. Savonchik, and V. I. Yanuchkovskii, "Studying thermal state of friction pairs of multidisc brake," Journal of Friction and Wear, vol. 34, no. 6, pp. 421-428, 2013.

[9] K. Devarajan and B. Balaram, "Analytical approximations for stick-slip amplitudes and frequency of duffing oscillator," Journal of Computational and Nonlinear Dynamics, vol. 12, no. 4, 2017.

[10] G. Liu and R. G. Parker, "Impact of tooth friction and its bending effect on gear dynamics," Journal of Sound and Vibration, vol. 320, no. 4-5, pp. 1039-1063, 2009.

[11] A. Rezaei, W. Van Paepegem, P. De Baets, W. Ost, and J. Degrieck, "Adaptive finite element simulation of wear evolution in radial sliding bearings," Wear, vol. 296, no. 1-2, pp. 660-671, 2012.

[12] E. Bortoleto, A. Rovani, V. Seriacopi et al., "Experimental and numerical analysis of dry contact in the pin on disc test," Wear, vol. 301, no. 1-2, pp. 19-26, 2013. 
[13] A. Lamjahdy, J. Ali, and B. Markert, "Simulation of the temperature and wear behaviour of a disc brake," Pamm, vol. 16, no. 1, pp. 217-218, 2016.

[14] G. Baldari, G. Logi, E. Fontana et al., "Numerical simulation on the coupling behavior between thermal load, contact stress and wear in a disc brake," Automotive Engineering, vol. 36, no. 8, pp. 984-988 and 979, 2014.

[15] F. Zhang, L. Gui, and Z. Fan, "Study on simulation of coupled heat transfer, stress and wear behavior in pin-on-disc experiments," Chinese Journal of Mechanical Engineering, vol. 51, no. 08, pp. 107-115, 2015 (Chinese).

[16] P. Hurricks, "Some metallurgical factors controlling the adhesive and abrasive wear resistance of steels. A review," Wear, vol. 26, no. 3, pp. 285-304, 1973.

[17] J. F. Archard, "Contact and rubbing of flat surfaces," Journal of Applied Physics, vol. 24, no. 8, pp. 981-988, 1953.

[18] I. V. Kragelsky, M. N. Dobychin, and V. S. Kombalov, "Friction and wear: calculation methods," Friction \& Wear, pp. 427-459, 1982.

[19] G. R. Johnson and W. H. Cook, "Fracture characteristics of three metals subjected to various strains, strain rates, temperatures and pressures," Engineering Fracture Mechanics, vol. 21, no. 1, pp. 31-48, 1985.

[20] J. Ning and S. Y. Liang, "Model-driven determination of Johnson-Cook material constants using temperature and force measurements," The International Journal of Advanced Manufacturing Technology, vol. 97, no. 1-4, pp. 1053-1060, 2018. 


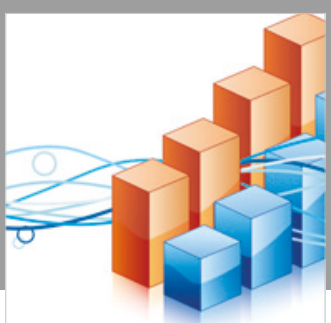

Advances in

Operations Research

\section{-n-m}
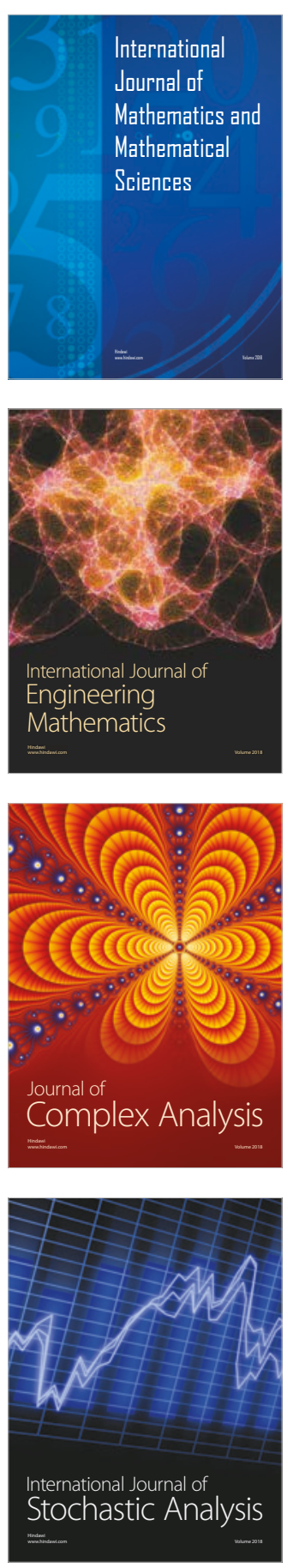
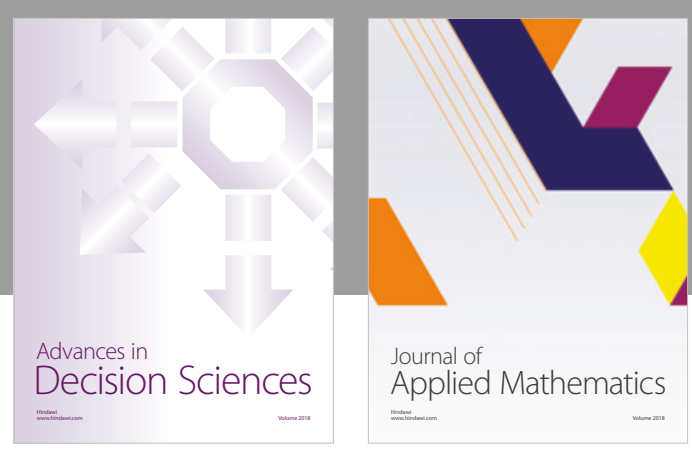

Journal of

Applied Mathematics
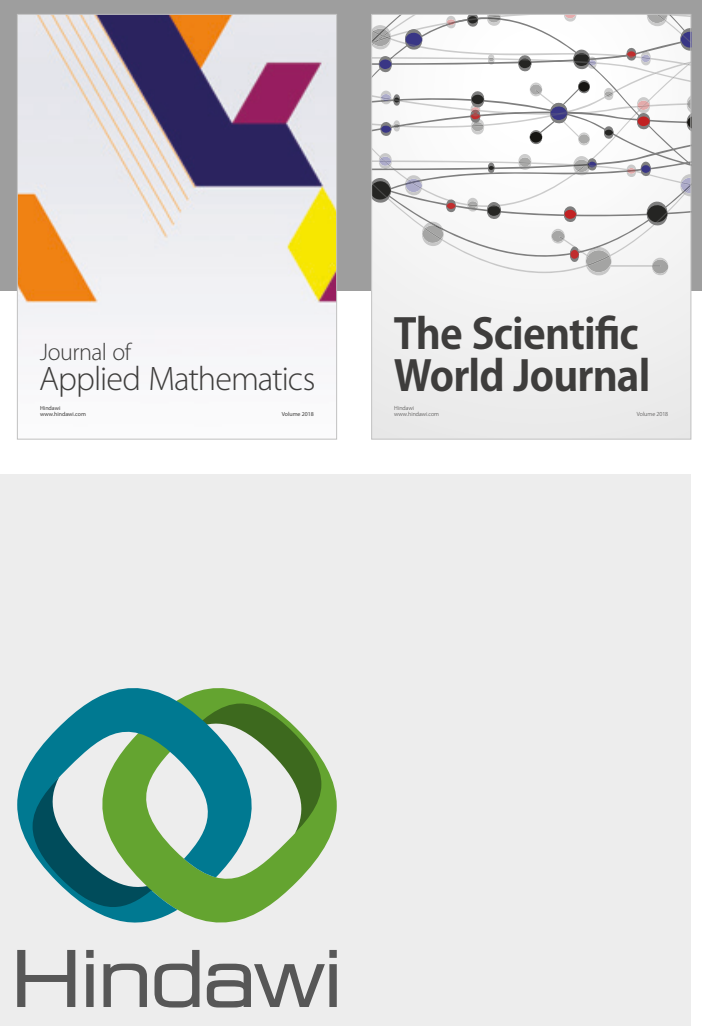

Submit your manuscripts at

www.hindawi.com

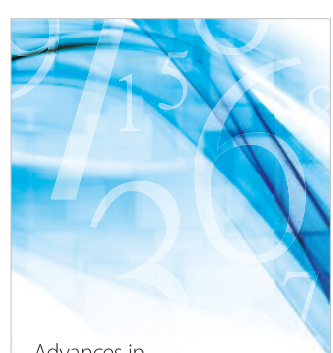

Advances in
Numerical Analysis
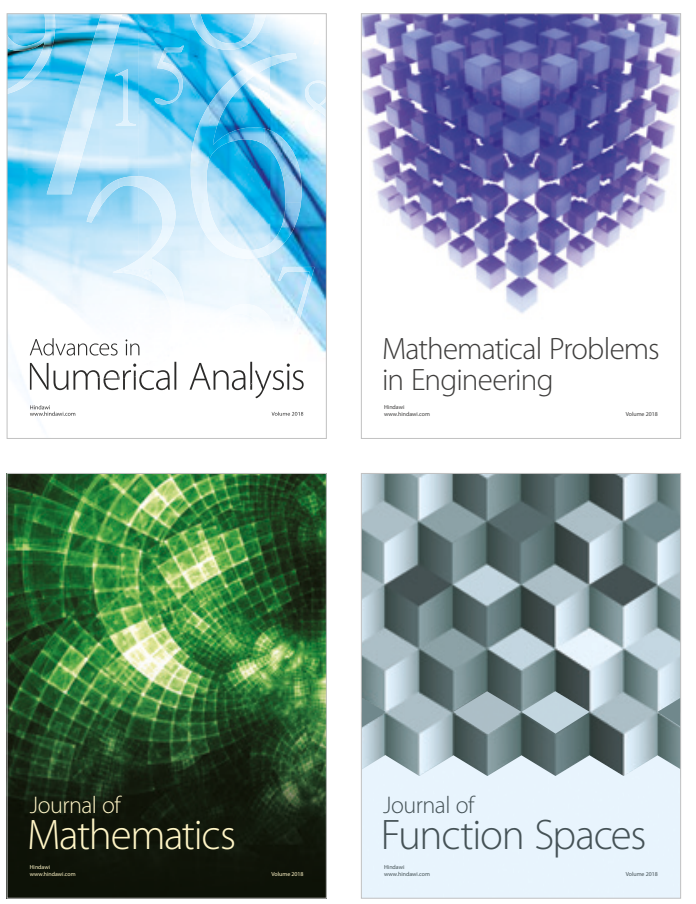

Mathematical Problems in Engineering

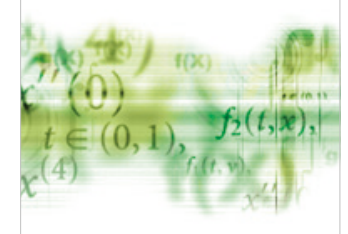

International Journal of

Differential Equations

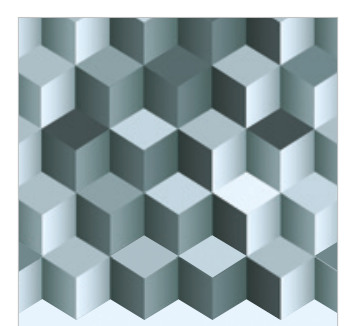

Journal of

Function Spaces

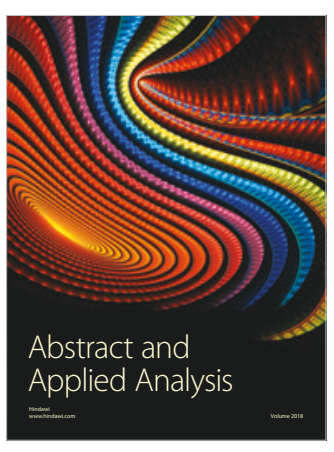

The Scientific

World Journal

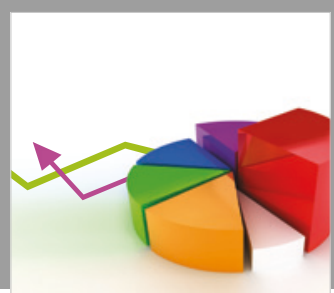

Journal of

Probability and Statistics
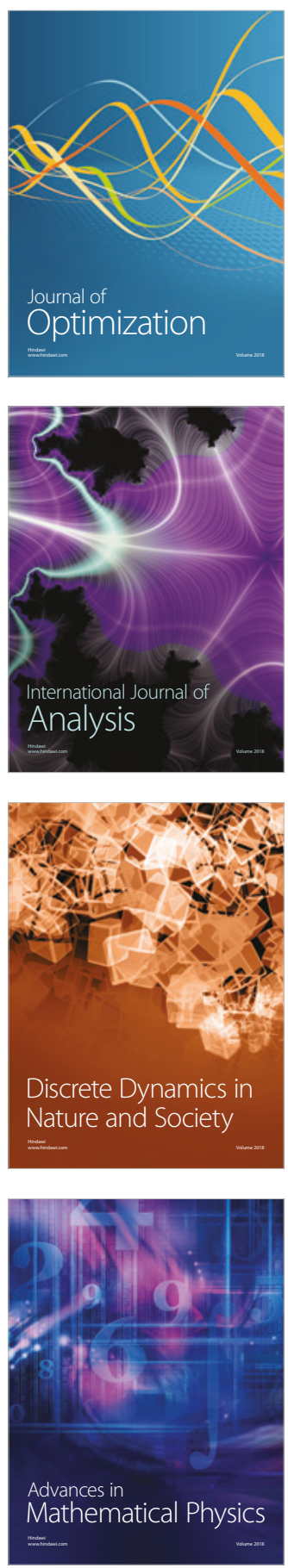